Annals of Pure and Applied Mathematics

Vol. 14, No. 1, 2017, 33-38

ISSN: 2279-087X (P), 2279-0888(online)

Published on 16 June 2017

www.researchmathsci.org

DOI: http://dx.doi.org/10.22457/apam.v14n1a4

Annals of

Pure and Applied

Mathematics

\title{
The Gourava Indices and Coindices of Graphs
}

\author{
V.R.Kulli
}

Department of Mathematics

Gulbarga University, Gulbarga 585106, India

e-mail: vrkulli@gmail.com

Received 3 June 2017; accepted 15 June 2017

Abstract. We introduce the first and second Gourava indices of a molecular graph. Also we introduce the first and second Gourava coindices of a molecular graph. In this paper, we compute the first and second Gourava indices of some standard classes of graphs. We also compute the first and second Gourava indices of armchair polyhex and zigzag-edge polyhex nanotubes.

Keywords: molecular graph, Gourava indices, Gourava coindices, nanotubes

AMS Mathematics Subject Classification (2010): 05C69, 05C12, 05 C35

\section{Introduction}

Let $G=(V, E)$ be a finite, simple, connected graph. The degree $d_{G}(v)$ of a vertex $v$ is the number of vertices adjacent to $v$. Any undefined term in this paper may be found in Kulli [1].

A molecular graph is a graph such that vertices correspond to the atoms and the edges to the bonds. Chemical graph theory is a branch of mathematical chemistry which has an important effect on the development of the chemical sciences. In chemical science, the physico-chemical properties of chemical compounds are often modeled by means of molecular graph based structure descriptors, which are also referred to as topological indices, see [2].

The first and second Zagreb indices, first appeared in a topological formula for the total $\pi$-energy of conjugated molecules, were introduced by Gutman et al. in [2]. These indices have been used as branching indices. The Zagreb indices have found applications in QSPR and QSAR studies.

The first and second Zagreb indices of a molecular graph $G$ are defined as

$$
M_{1}(G)=\sum_{u v \in(G)}\left[d_{G}(u)+d_{G}(v)\right], \quad M_{2}(G)=\sum_{u v \in E(G)} d_{G}(u) d_{G}(v) .
$$

Motivated by the definitions of the Zagreb indices and their wide applications, we introduce the first Gourava index of a molecular graph as follows:

The first Gourava index of a graph $G$ is defined as

$$
G O_{1}(G)=\sum_{u v E(G)}\left[\left(d_{G}(u)+d_{G}(v)\right)+d_{G}(u) d_{G}(v)\right] \text {. }
$$


V.R.Kulli

The generalized Zagreb index was introduced by Azari and Iranmanesh in [3] and is defined as

$$
M_{r, s}(G)=\sum_{u v \in E(G)}\left(d_{G}(u)^{r} d_{G}(v)^{s}+d_{G}(v)^{r} d_{G}(u)^{s}\right), \text { for all } r, s \in N
$$

Motivated by the definitions of the first Gourava index and the generalized Zagreb index, we define the second Gourava index of a molecular graph $G$ as follows:

The second Gourava index of a molecular graph $G$ is defined as

$$
G O_{2}(G)=\sum_{u v \in E(G)}\left(d_{G}(u)+d_{G}(v)\right)\left(d_{G}(u) d_{G}(v)\right) \text {. }
$$

We rewrite the second Gourava index as follows:

$$
G O_{2}(G)=\sum_{u v \in E(G)}\left(d_{G}(u)^{2} d_{G}(v)+d_{G}(v)^{2} d_{G}(u)\right) .
$$

Recently many topological indices were studied, for example, in $[4,5,6,7,8,9$, $10,11,12,13,14,15,16]$.

In this paper, we consider the armchair polyhex nanotubes $T U A C_{6}[m, n]$ and zigzag-edge polyhex nanotubes $T U Z C_{6}[m, n]$, and compute their Gourava indices. Also the first and second Gourava indices of some standard classes of graphs are determined.

\section{Results for some standard classes of graphs}

Proposition 1. Let $C_{n}$ be a cycle with $n \geq 3$ vertices. Then $G O_{1}\left(C_{n}\right)=8 n$.

Proof: Let $C_{n}$ be a cycle with $n \geq 3$ vertices. Then $G O_{1}\left(C_{n}\right)=n[(2+2)+(2 \times 2)]=8 n$.

Proposition 2. Let $K_{n}$ be a complete graph with $n \geq 2$ vertices. Then

$$
G O_{1}\left(K_{n}\right)=\frac{1}{2} n(n+1)(n-1)^{2} \text {. }
$$

Proof: Let $K_{n}$ be a complete graph with $n$ vertices. Then $K_{n}$ has $\frac{n(n-1)}{2}$ edges.

$$
G O_{1}\left(K_{n}\right)=\frac{n(n-1)}{2}[(n-1)+(n-1)+(n-1)(n-1)]=\frac{n(n-1)^{2}(n+1)}{2} .
$$

Proposition 3. Let $K_{m, n}$ be a complete bipartite graph with $1 \leq m \leq n$. Then

$$
G O_{1}\left(K_{m, n}\right)=m n(m+n+m n) \text {. }
$$

Proof: Let $K_{m, n}$ be a complete bipartite graph with $1 \leq m \leq n$. Then $K_{m, n}$ has $m+n$ vertices and $m n$ edges such that $\left|V_{1}\right|=m,\left|V_{2}\right|=n, V\left(K_{m, n}\right)=V_{1} \cup V_{2}$. Clearly every vertex of $V_{1}$ is adjacent with $n$ vertices and every vertex of $V_{2}$ is adjacent with $m$ vertices.

$$
G O_{1}\left(K_{m, n}\right)=m n[(m+n)+m n] .
$$

Corollary 3.1. Let $K_{n, n}$ be a complete bipartite graph. Then $G O_{1}\left(K_{n, n}\right)=n^{3}(2+n)$.

Corollary 3.2. Let $K_{1, n}$ be a star. Then $G O_{1}\left(K_{1, n}\right)=n(1+2 n)$.

Proposition 4. If $G$ is an $r$-regular graph with $n$ vertices, then 
The Gourava Indices and Coindices of Graphs

$$
G O_{1}(G)=\frac{1}{2} n r^{2}(2+r) .
$$

Proof. If $G$ is an $r$-regular graph with $n$ vertices, then $G$ has $n r / 2$ edges. The degree of each vertex of $G$ is $r$.

$$
G O_{1}(G)=\frac{n r}{2}\left[(r+r)+r^{2}\right]=\frac{1}{2} n r^{2}(2+r) .
$$

Proposition 5. Let $P_{n}$ be a path with $n \geq 3$ vertices. Then $G O_{1}\left(P_{n}\right)=8 n-14$.

Proof: Let $G=P_{n}$ be a path with $n \geq 3$ vertices. We obtain two partitions of the edge set of $P_{n}$ as follows:

$$
\begin{aligned}
& E_{3}=\left\{u v \in E(G) \mid d_{G}(u)=1, d_{G}(v)=2\right\}, \quad\left|E_{3}\right|=2 . \\
& E_{4}=\left\{u v \in E(G) \mid d_{G}(u)=d_{G}(v)=2\right\}, \quad\left|E_{4}\right|=\mathrm{n}-3 .
\end{aligned}
$$

To compute $G O_{1}\left(P_{n}\right)$, we see that

$$
\begin{aligned}
G O_{1}(G) & =\sum_{u \in E(G)}\left[\left(d_{G}(u)+d_{G}(v)\right)+\left(d_{G}(u) d_{G}(v)\right)\right] \\
& =[(1+2)+(1 \times 2)] 2+[2+2)+(2 \times 2)](\mathrm{n}-3) . \\
& =10+8 n-24=8 n-14 .
\end{aligned}
$$
determined.

Similarly, the second Gourava index of some standard classes of graphs are

Proposition 6. (1) Let $C_{n}$ be a cycle with $n \geq 3$ vertices. Then $G_{2}\left(C_{n}\right)=16 n$.

(2) Let $K_{n}$ be a complete graph with $n \geq 2$ vertices. Then $G O_{2}\left(K_{n}\right)=n(n-1)^{4}$.

(3) $K_{m, n}$ be a complete bipartite graph with $1 \leq m \leq n$. Then

$$
G O_{2}\left(K_{m, n}\right)=(m+n) \mathrm{m}^{2} \mathrm{n}^{2} .
$$

(4) If $G$ is an $r$-regular graph with $n$ vertices, then $G O_{2}(G)=n r^{4}$.

(5) Let $P_{n}$ be a path with $n \geq 3$ vertices. Then $G O_{2}\left(P_{n}\right)=16 n-36$.

\section{Results for armchair polyhex nanotubes}

The armchair polyhex nanotubes usually symbolized as $\operatorname{TUAC}_{6}[m, n]$ in which $m$ is the number of hexagons in first row and $n$ is the number of rows. The graph of $T U A C_{6}[m, n]$ is shown in Figure 1.

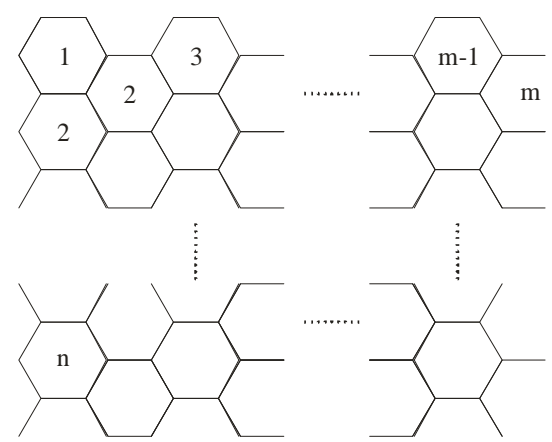

Figure 1: The graph of armchair polyhex nanotube $T U A C_{6}[m, n]$ 
By algebraic method, we obtain $\left|V\left(\operatorname{TUAC}_{6}[m, n]\right)\right|=2 m(n+1)$ and $\mid E\left(T U A C_{6}[m\right.$, $n]) \mid=3 m n+2 m$. Let $G=T U A C_{6}[m, n]$.

Also by algebraic method, we obtain three edge partitions of $\left(T U A C_{6}[m, n]\right)$ based on the sum of degrees of the end vertices as follows:

$$
\begin{aligned}
& E_{4}=\left\{u v \in E(G) \mid d_{G}(u)=2, d_{G}(v)=2\right\}, \quad\left|E_{4}\right|=m . \\
& E_{5}=\left\{u v \in E(G) \mid d_{G}(u)=2, d_{G}(v)=3\right\}, \quad\left|E_{5}\right|=2 m . \\
& E_{6}=\left\{u v \in E(G) \mid d_{G}(u)=d_{G}(v)=3\right\}, \quad\left|E_{4}\right|=3 m n-m .
\end{aligned}
$$

In the following theorem, we determine the first and second Gourava indices of the $\operatorname{TUAC}_{6}[m, n]$ nanotube.

Theorem 1. The first and second Gourava indices of $\operatorname{TUAC}_{6}[m, n]$ nanotube are respectively given by

i) $\quad G O_{1}\left(T U A C_{6}[m, n]\right)=45 m n+15 m$.

ii) $\quad G_{2}\left(T_{U A C}[m, n]\right)=162 m n+22 m$.

Proof: Let $G=T U A C_{6}[m, n]$. The graph $G$ has $2 m(n+1)$ vertices and $3 m n+2 m$ edges.

i) From equation (1), we have

$$
G O_{1}(G)=\sum_{u v E E(G)}\left[\left(d_{G}(u)+d_{G}(v)\right)+\left(d_{G}(u) d_{G}(v)\right)\right]
$$

Using the cardinalities of the edge partitions of $G$, we have

$$
\begin{aligned}
G O_{1}(G) & =m[(2+2)+(2 \times 2)]+2 m[(2+3)+(2 \times 3)]+(3 m n-m)[(3+3)+(3 \times 3)] \\
& =8 m+22 m+(3 m n-m) 15 \\
& =45 m n+15 m .
\end{aligned}
$$

ii) From equations (2), we have

$$
G O_{2}(G)=\sum_{u v E(G)}\left(d_{G}(u) d_{G}(v)\right)\left(d_{G}(u) d_{G}(v)\right) .
$$

Using the cardinalities of the edge partitions of $G$, we have

$$
\begin{aligned}
G O_{2}(G) & =m[(2+2) \times(2 \times 2)]+2 m[(2+3) \times(2 \times 3)]+(3 m n-m)[(3+3) \times(3 \times 3)] \\
& =16 m+60 m+(3 m n-m) 54 \\
& =162 m n+22 m .
\end{aligned}
$$

\section{Results for Zigzag-edge polyhex nanotubes}

The zigzag-edge polyhex nanotubes usually symbolized as $\operatorname{TUZC}_{6}[m, n]$ in which $m$ is the number of hexagons in the first row and $n$ is the number of rows. The graph of $\operatorname{TUZC}_{6}[m, 3]$ is shown in Figure 2.
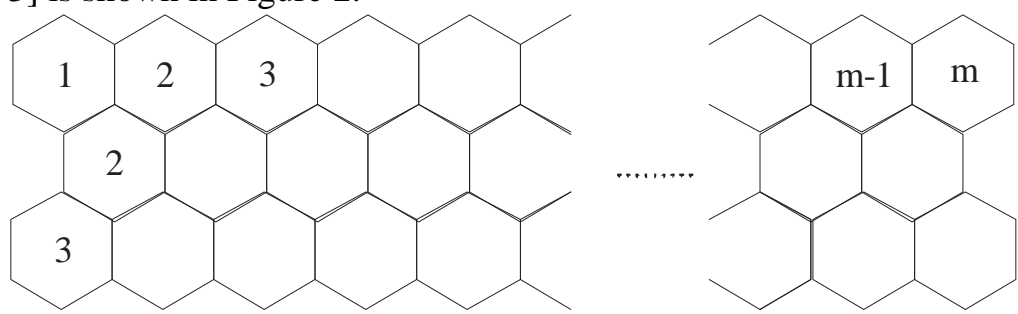

Figure 2: The graph of zigzag-edge polyhex nanotube $T U Z C_{6}[m, 3]$

By algebraic method, we obtain $\left|V\left(T U Z C_{6}[m, n]\right)\right|=2 m(n+1)$ and $\mid E\left(T U Z C_{6}[m\right.$, $n]) \mid=3 m n+2 m$. Let $H=T U Z C_{6}[m, n]$. 
The Gourava Indices and Coindices of Graphs

Also by algebraic method, we obtain two edge partitions of $T U Z C_{6}[m, n]$ based on the sum of degrees of the end vertices as follows:

$$
\begin{array}{ll}
E_{5}=\left\{u v \in E(H) \mid d_{H}(u)=2, d_{H}(v)=3\right\}, & \left|E_{5}\right|=4 m . \\
E_{6}=\left\{u v \in E(H) \mid d_{H}(u)=d_{H}(v)=3\right\}, & \left|E_{6}\right|=3 m n-2 m .
\end{array}
$$

In the following theorem, we determine the first and second Gourava indices of the $T U Z C_{6}[m, n]$ nanotube.

Theorem 2. The first and second Gourava indices of $\operatorname{TUZC}_{6}[m, n]$ nanotube are respectively given by

i) $\quad G O_{1}\left(T U Z C_{6}[m, n]\right)=45 m n+14 m$.

ii) $\quad G_{2}\left(T U Z C_{6}[m, n]\right)=162 m n+12 m$.

Proof: Let $H=T U Z C_{6}[m, n]$. The graph $H$ has $2 m(n+1)$ vertices and $3 m n+2 m$ edges.

i) From equation (1), we have

$$
G O_{1}(H)=\sum_{u v \in E(H)}\left[\left(d_{H}(u)+d_{H}(v)\right)+\left(d_{H}(u) d_{H}(v)\right)\right]
$$

Using the cardinalities of the edge partitions of $H$, we have $G O_{1}(H)=4 m[(2+3)+(2 \times 3)]+(3 m n-2 m)[(3+3)+(3 \times 3)]$

$$
=44 m+45 m n-30 m=45 m n+14 m \text {. }
$$

ii) From equation (2), we have

$$
G O_{2}(H)=\sum_{u v E(H)}\left(d_{G}(u)+d_{G}(v)\right)\left(d_{G}(u) d_{G}(v)\right) .
$$

Using the cardinalities of the edge partitions of $H$, we have $G_{2}(H)=4 m[(2+3) \times(2 \times 3)]+(3 m n-2 m)[(3+3) \times(3 \times 3)]$

$=120 m+(3 m n-2 m) 54=162 m n+12 m$.

\section{The first and second gourava coindices}

We introduce the first and second Gourava coindices of a molecular graph. defined as

The first and second Gourava coindices of a molecular graph $G$ are respectively

$$
\begin{aligned}
& \overline{G O_{1}}(G)=\sum_{u v \notin E(G)}\left[\left(d_{G}(u)+d_{G}(v)\right)+d_{G}(u) d_{G}(v)\right], \\
& \overline{G O_{2}}(G)=\sum_{u v \notin E(G)}\left(d_{G}(u)+d_{G}(v)\right) d_{G}(u) d_{G}(v) .
\end{aligned}
$$

\section{REFERENCES}

1. V.R.Kulli, College Graph Theory, Vishwa International Publications, Gulbarga, India (2012).

2. I.Gutman and N.Trinajstić, Graph theory and molecular orbitals. Total $\square$-electron energy of alternant hydrocarbons, Chem. Phys. Lett., 17 (1972) 535-538.

3. M.Azari and A.Iranmanesh, Generalized Zagreb index of graphs, Studia Univ. BabesBolyai, 56(3) (2011) 59-70.

4. V.R.Kulli, On $K$ indices of graphs, International Journal of Fuzzy Mathematical Archive, 10(2) (2016) 105-109. 
5. V.R. Kulli, On $K$ - edge index and coindex of graphs, International Journal of Fuzzy Mathematical Archive, 10(2) (2016) 111-116.

6. V.R.Kulli, The first and second $k a$ indices and coindices of graphs, International Journal of Mathematical Archive, 7(5) (2016) 71-77.

7. V.R.Kulli, Multiplicative connectivity indices of $T U C_{4} C_{8}[m, n]$ and $T U C_{4}[m, n]$ nanotubes, Journal of Computer and Mathematical Sciences, 7(11) (2016) 599-605.

8. V.R.Kulli, On multiplicative $K$-Banhatti and multiplicative $K$ hyper-Banhatti indices of $V$-Phenylenic nanotubes and nanotorus, Annals of Pure and Applied Mathematics, 11(2) (2016) 145-150.

9. V.R.Kulli, Computation of general topological indices for titania nanotubes, International Journal of Mathematical Archive, 7(12) (2016) 33-38.

10. V.R.Kulli, Multiplicative connectivity indices of nanostructures, Journal of Ultra Scientist of Physical Sciences, A 29(1) (2017) 1-10.

DOI: http://dx.doi.org/10.22147/jusps-A/290101.

11. V.R.Kulli, Two new multiplicative atom bond connectivity indices, Annals of Pure and Applied Mathematics, 13(1) (2017) 1-7.

DOI: http://dx.doi.org/10.22457/apam.vl3nlal.

12. V.R.Kulli, Some new multiplicative geometric-arithmetic indices, Journal of Ultra Scientist of Physical Sciences, A, 29(2) (2017) 52-57. DOI: http://dx.doi.org/10.22147/jusps-A/290201.

13. V.R.Kulli, Computation of some topological indices of certain networks, International Journal of Mathematical Archive, 8(2) (2017) 99-106.

14. V.R.Kulli, New K.Banhatti topological indices, International Journal of Fuzzy Mathematical Archive, 12(1) (2017) 29-37.

DOI: http://dx.doi.org/10.22457/ijfma.v12n1a4.

15. V.R.Kulli, New arithmetic-geometric indices, Annals of Pure and Applied Mathematics, 13(2) (2017) 165-172.

DOI: http://dx.doi.org/10.22457/apam.13n2a2.

16. V.R.Kulli, A new multiplicative arithmetic-geometric index, International Journal of Fuzzy Mathematical Archive, 12(2) (2017) 49-53.

DOI: http://dx.doi.org/10.22457/ijfma.v12n2a1. 